\title{
A resolutividade da prática de grupos educativos por enfermeiros na atenção primária
}

\author{
Mariana Pereira Nunes Fonseca, Fabiana de Andrade Coutinho, Laís Pimenta, Letícia Vieira \\ Lourenço, Thamires Simão Marques, Ana Carolina Fiuza Moreira
}

\section{Resumo}

A diabetes mellitus (DM) é um distúrbio metabólico crônico, comum nos consultórios da atenção primária do Rio de Janeiro. Caracterizada pela disfunção metabólica da glicose, é responsável pelo desenvolvimento de neuropatias que configura o principal fator causal de ulcerações e amputações ocasionando prejuízos tanto emocionais ao usuário quanto financeiro ao município. Nesse sentido, é fundamental que durante o atendimento ao usuário diabético na atenção primária garanta não só o controle clínico da glicemia, mas também a vigilância dos pés através do exame clínico. No entanto, diante do elevado ritmo de atendimentos, por vezes a avaliação dos pés nem sempre é realizada durante a consulta. Dessa forma, é necessário que a equipe técnica lance mão de outras estratégias de abordagem aos usuários, de modo a garantir a abordagem integral e preventiva. Descrever a experiência de um grupo sobre pé diabético realizado em uma Unidade Básica de Saúde. A partir da discussão em uma reunião de equipe a respeito de grupos que devem ser prioritários, identificou-se a necessidade de se realizar um grupo de pé diabético. $O$ grupo contou com onze usuários, sendo a oito mulheres e três homens, com faixa etária entre 40 e 80 anos. O grupo aconteceu em uma Clínica da Família, localizada no bairro Penha, no município do Rio de Janeiro. A atividade foi coordenada por duas enfermeiras residentes contando com o apoio de um agente comunitário de saúde, em uma quinta-feira no mês de junho de 10h00min ás $12 \mathrm{~h} 00 \mathrm{~min}$. A atividade foi separada em dois momentos: o primeiro com uma apresentação de slides estimulando a participação dos usuários, trazendo questões pertinentes da diabetes, ressaltando as complicações e orientações a respeito dos cuidados com os pés, estimulando principalmente o autocuidado. $\mathrm{O}$ segundo momento foi contemplado pela avaliação dos pés através do teste de sensibilidade, utilizando os monofilamentos. Os usuários mostraram-se interessados pelo assunto, participando, trazendo dúvidas e contribuições de experiências vivenciadas. Ao final todos aceitaram realizar o teste de sensibilidade, uma vez que perceberam a importância do cuidado com os pés para impedir complicações evitáveis e além disso, pudemos identificar aqueles que apresentaram alguma perda da sensibilidade. É notório que a prevenção por meio do exame frequente dos pés de pessoas com diabetes, que pode ser realizado tanto pelo médico como pela enfermeira, é de vital importância para a redução das complicações. Além disso, se torna evidente a importância do rastreamento das pessoas com diabetes, para identificar as com maior risco para ulceração nos pés, que podem se beneficiar com as orientações profiláticas, incluindo o estímulo ao autocuidado.

Descritores: Diabetes mellitus; Pé diabético; Atenção primária 